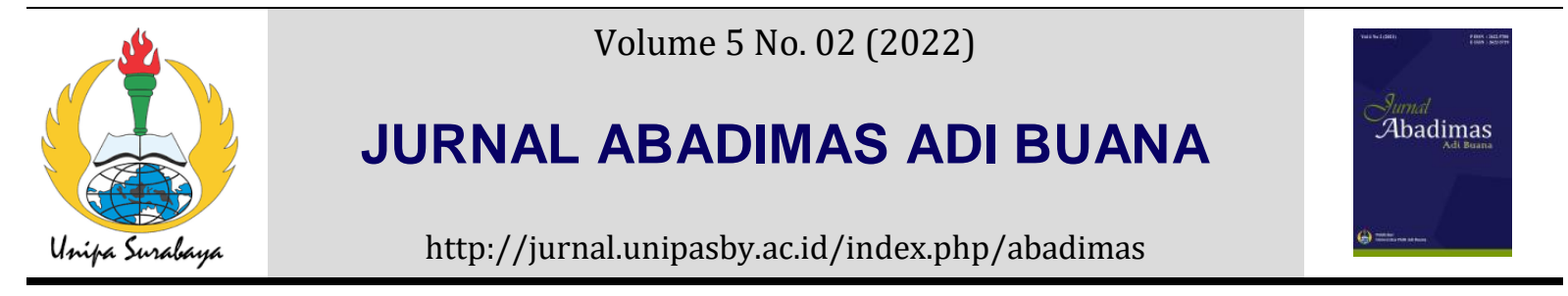

\title{
PENGENALAN PENTINGNYA CYBER SECURITY AWARENESS PADA UMKM
}

\author{
I Made Suartana ${ }^{1 *}$, Ricky Eka Putra ${ }^{1}$, Rahadian Bisma ${ }^{2}$, Aditya Prapanca ${ }^{3}$ \\ ${ }^{1}$ Prodi Teknik Informatika, Jurusan Teknik Informatika, Universitas Negeri Surabaya \\ ${ }^{2}$ Prodi Sistem Informasi, Jurusan Teknik Informatika, Universitas Negeri Surabaya \\ ${ }^{3}$ Prodi Pendidikan Teknologi Informasi, Jurusan Teknik Informatika, Universitas Negeri Surabaya \\ *email: madesuartana@unesa.ac.id
}

Informasi Artikel Abstrak

\section{Kata kunci:}

UMKM, Cyber-

Security, Pandemicovid-19

Diterima: 21-11-2021

Disetujui: 10-01-2022

Dipubikasikan: 28-01-

2022

Keywords:

MSMEs, Cyber-

Security, Covid-19

Pandemic
Meningkatnya transformasi digital sebagai efek dari pademi COVID-19 menuntu UMKM untuk memanfaatkan media digital menggantikan proses jual-beli secara konvensional. Selain dampak positif tranformasi digital juga berpotensi menimbulkan dampak negatif. Disisi lain kriminalitas cyber juga menjadi suatu ancaman yang serius bagi tranformasi digital. Maraknya serangan siber yang menyasar UMKM karena UMKM dinilai sebagai target yang potensial karena jarang memperhatikan keamanan dan perlindungan data informasi termasuk identitas pelanggan. Kelengahan pengguna ketika mengakses internet dapat mengakibatkan resiko-resiko dan kerugian tertentu. Beberapa kerugian tersebut di antaranya adalah menyangkut masalah privasi (kerahasiaan pribadi pengguna), masalah yang terkait dengan finansial UMKM, permasalahan etika, dan lain sebagainya. Pengenalan Cyber Security Awareness kepada pelaku UMKM sebagai langkah awal dalam mengedukasi pelaku UMKM agar memiliki kesadaran akan bahaya dalam proses transaksi secara digital melalui internet. Manfaat yang diperoleh bagi UMKM melalui melalui pelaksanaan pengabdian kepada masyarakat ini adalah mendapatkan pengetahuan tentang pentingnya kesadaraan tentang ancaman keamanan dalam dunia digital. Serta UMKM memiliki pengetahuan untuk dapat terhindar dari kemungkinan tindak kejahatan cyber.

\section{Abstract}

The increasing digital transformation resulting from the COVID-19 pandemic requires MSMEs to utilize digital media for replacing the conventional buying and selling process. In addition to the positive impact of digital transformation, it also can cause harmful effects. On the other hand, cybercrime is also a severe threat to digital transformation. The rise of cyber attacks targeting MSMEs is because MSMEs are considered potential targets. After all, they rarely pay attention to the security and protection of information data, including customer identities. User carelessness when accessing the internet can result in certain risks and losses. Some of these losses include privacy (user privacy), problems related to MSME finance, ethical issues, and so on. The introduction of Cyber Security Awareness to MSME actors is the first step in educating 
MSME actors to be aware of the dangers in the digital transaction process via the internet. The benefits obtained for MSMEs through the implementation of community service are gaining knowledge about the importance of awareness about security threats in the digital world. And MSMEs know to be able to avoid the possibility of cybercrime.

\section{PENDAHULUAN}

Selain membawa dampak positif tranformasi digital juga berpotensi menimbulkan dampak negatif. Disisi lain kriminalitas cyber juga menjadi suatu ancaman yang serius bagi tranformasi digital yang marak belakangan ini. Pada triwulan pertama tahun 2020 di kawasan Asia tenggara, terdeteksi ratusan ribu serangan phising yang menyasar pelaku usaha mikro kecil menengah (UMKM). Adapun serangan terhadap UMKM di Indonesia terdapat laporan lebih dari 192 ribu serangan(Cindy Mutia Annur, 2020). Banyaknya serangan siber yang menjadikan UMKM sebagai target serangan dikarenakan UMKM dinilai sebagai target yang potensial. Secara umum dinilai UMKM jarang memperhatikan hal-hal yang terkait dengan keamanan dan perlindungan data termasuk identitas pelanggan. Maraknya kasus kejahatan siber seharusnya menjadi pengingat bagi pelaku UMKM yang menggunakan media internet untuk lebih berhati-hati. Ketidakwaspadaan ketika pengguna mengakses internet dapat mengakibatkan terjadinya serangan dan menimbulkan resiko-resiko dan kerugian. Kerugian akibat serangan siber umunya menyangkut masalah privasi (kerahasiaan pribadi pengguna), masalah terkait dengan finansial UMKM, permasalahan etika, dan lain sebagainya (Li \& Liu, 2021).

Maraknya serangan yang menyasar UMKM secara tidak langsung merupakan efek dari pandemi COVID-19 dalam hal ini bagi UMKM adalah keharusan atau pergeseran proses terutama jual beli dan promosi yang awalnya lebih banyak secara luar jaringan (luring) menjadi proses yang lebih banyak memanfaatkan media digital dan internet secara daring (dalam jaringan)(Widnyani et al., 2021). Kurangnya edukasi dan pengenalan terkait cyber security kepada pelaku UMKM, sehingga banyak yang belum menyadari bahaya serangan terhadap keamaan siber. Oleh karena itu, para pelaku UMKM harus memiliki kesadaran akan kejahatan dunia maya (cyber crime awareness) supaya kerugian dan resiko dari penggunaan internet seperti untuk penjualan, pemasaran, bisnis, dan berkomunikasi dengan pihak lain dapat diminimalisir (Nugrahani et al., 2019).

Pentingnya keamaanan siber diungkapkan (Alkhudhayr et al., 2019) yang menyatakan melindungi informasi perusahaan dan keamanan informasi sangat penting untuk dijaga. Keamanan informasi didefinisikan sebagai melindungi informasi, sistem, dan perangkat keras yang menggunakan, menyimpan dan mengirimkan informasi, untuk memastikan integritas, kerahasiaan dan ketersediaan data. Sedangkan (Jixing et al., 2018) mengungkapkan bahwa serangan siber yang muncul semakin serius akibat kurangnya kesadaran terkait dengan bahaya siber itu sendiri. 
Edukasi terkait serangan siber sudah dilakukan dibeberapa kegiatan pengabdian seperti (Miftahurrisqi et al., 2021) memberikan edukasi dan peningkatan kompetensi it-security dan ecommerce bagi mahasiswa. (Khairunnisak Nur Isnaini et al., 220 C.E.) melaksanakan seminar sebagai upaya peningkatan literasi tentang cyber attacks dan ancaman cyber.

Pelaksanaan kegiatan pengabdian ini mengusulkan pengenalan Cyber Security Awareness yang difokuskan kepada pelaku UMKM. Kegitan ini sebagai langkah awal dalam mengedukasi pelaku UMKM agar memiliki kesadaran akan bahaya dalam proses transaksi secara digital melalui internet.

\section{METODE}

Pelaksanaan Pengabdian Kepada Masyarakat tercantum dalam metodologi pelaksanaan yang dapat dilihat pada gambar 1.

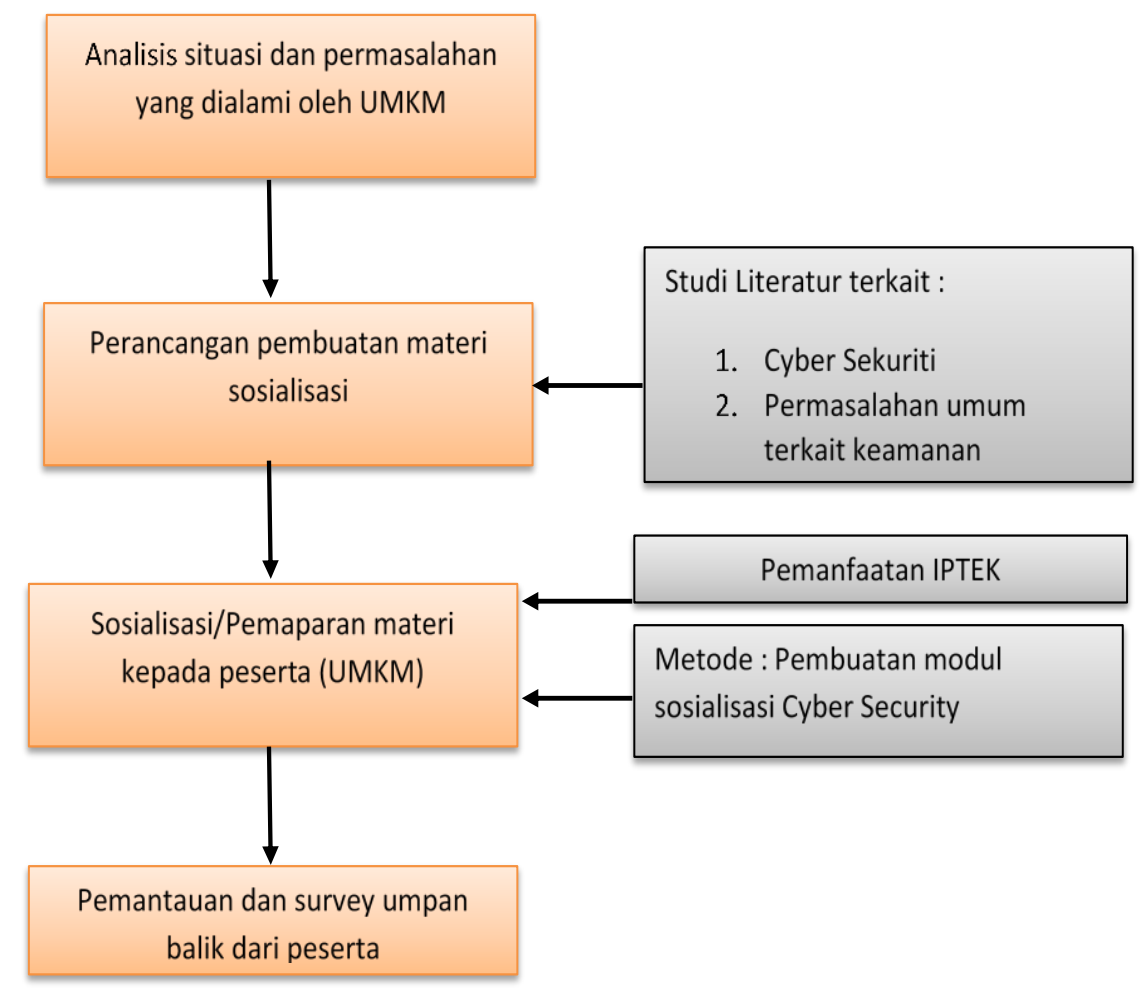

Gambar 1. Metode Pelatihan pengenalan Cyber Security

Pada tahap pertama, kegiatan PKM ini dimulai dengan penganalisisan situasi dan kondisi serta pendefinisian permasalahan-permasalahan yang ada pada UMKM mitra. Isu-isu mengenai serangan atau permasalahan keamanan yang umum juga ditinjau sebagai dasar menentukan materi sosialiasasi kepada mitra.

Tahap kedua adalah perancangan mekanisme sosialisasi pelatihan yang akan disampaikan kepada mitra. Dalam tahap ini juga dilaksanakan pembuatan materi atau modul yang akan disampaiakan dan diberikan kepada peserta atau mitra. 
Tahap selanjutnya adalah sosialisasi atau pelatihan kepada mitra. Sosialisasi atau pelatihan dengan memaparkan materi-materi sesuai dengan permasalahan atau kebutuhan dari mitra.

Kegiatan akhir dari pelaksanaan kegiatan pengabdian ini adalah pemantauan dan penilaian pelaksanaan kegiatan. Penilaian pelaksanaan kegitatan pengabdian ini berdasarkan survei terhadap kepuasan mitra terkait pelatihan yang dilaksanakan.

\section{HASIL DAN PEMBAHASAN}

\section{Hasil Analisis Situasi}

Pelaksanaan edukasi kepada UMKM terkait pengenalan pentingnya cyber security awareness dimulai dari tahap analisis situasi. Proses identifikasi permasalahan mitra dilaksanakan melalui diskusi dari tim pelaksana PKM dengan perwakilan mitra, dengan menggunakan media komunikasi online. Dari beberapa kali diskusi secara online, maka tim mendapat gambaran pengunaan teknologi oleh UMKM dan permaslahan-pemrasalahan yang dihadapi UMKM terutama terkait pengunaan teknologi dalam usaha mereka. Berdasarkan analisis berdasarkan analisis situasi dapat diidentifikasi permasalahan mitra yaitu : Efek dari pandemi covid-19 dalam hal ini bagi UMKM adalah keharusan atau pergeseran proses terutama jual beli dan promosi yang awalnya lebih banyak secara luar jaringan (luring) menjadi proses yang lebih banyak memanfaatkan media digital dan internet secara daring (dalam jaringan).

Dari beberapa mitra UMKM dengan berbagai bidang usaha seperti : jasa, fashion, makanan, kuliner, dan lain-lain seperti digambarkan pada Gambar 2. Sekitar 92.3\% menggunakan media online dalam usahanya dan kurang dari 10\% masih menggunakan media ofline, seperti pada gambar 3 .

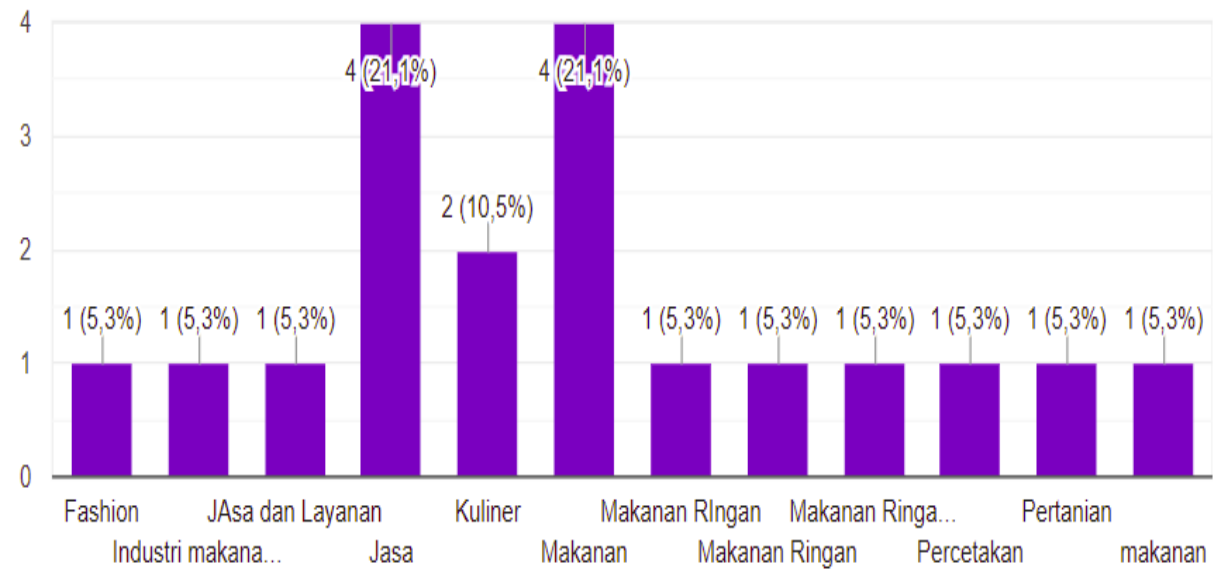

Gambar 2. Sebaran jenis usaha 


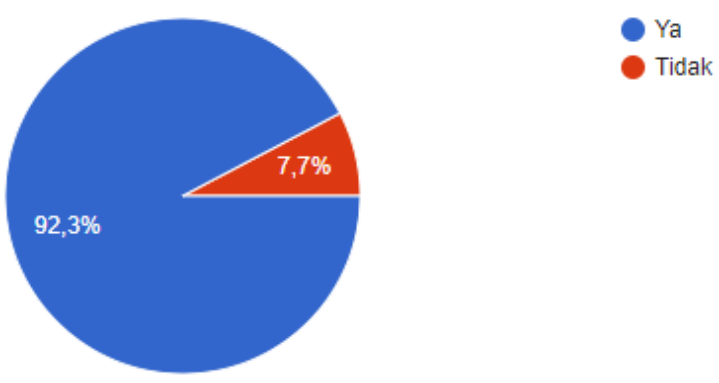

Gambar 3. Pemanfaatan media online

Kurangnya edukasi dan pengenalan terkait cyber security kepada pelaku UMKM, sehingga banyak yang belum menyadari bahaya serangan terhadap keamaan siber. Dari survei terhadap mitra masih sekitar $23.1 \%$ yang belum pernah mendengar terkait keamanan siber, dan sekitar $73.9 \%$ pernah mendengar terkait keamanan siber, seperti yang ditunjukkan pada gambar 4 .

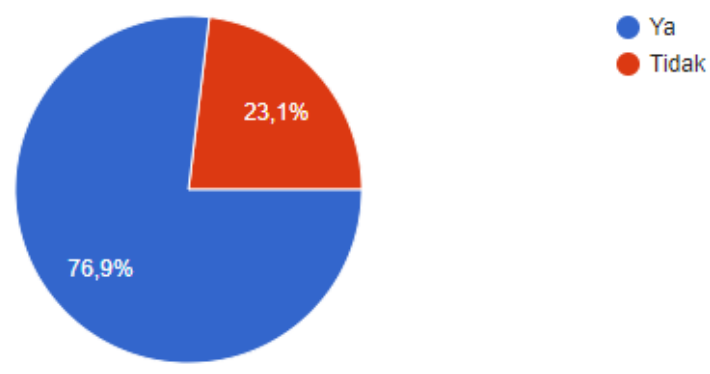

Gambar 4. Responden yang mengetahui tentang keamanan siber

Sedangkan terkait kepedulian responden terhadap keamanan siber masih terdapat $7.7 \%$ responden yang tidak peduli terhadap keamanan siber. 15.4\% khawatir terhadap ancaman keamanan siber akan tetapi masih mengalami kebingungan terkait tindakan apa yang perlu dilakukan baik untuk pencegahan atau penanggulangan. Sedangkan $76.9 \%$ responden mengaku khawatir terkait dengan bahaya ancaman siber. Seperti pada gambar 5.

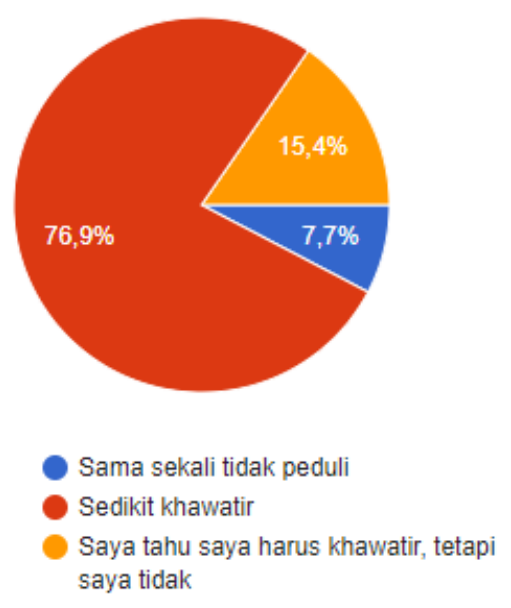

Gambar 5. Respon kepedulian terhadap keamanan siber 
Dari data yang didapat responden yang pernah mengalami kejadian atau serangan terhadap keamanan siber cukup tinggi, sebanyak $46.2 \%$ mengakui pernah mengalami serangan siber. Seperti yang digambarkan pada gambar 6.

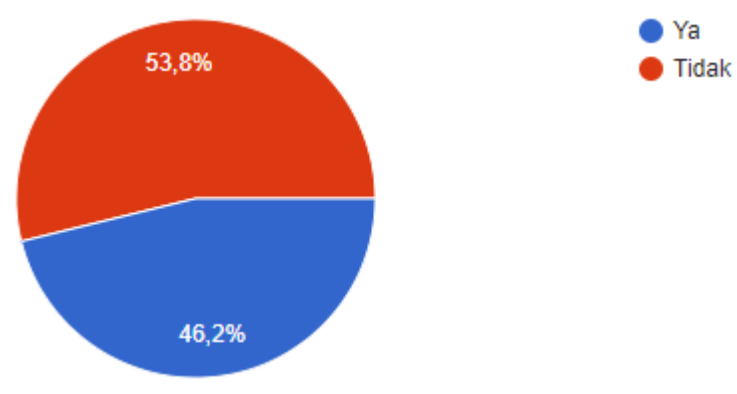

Gambar 6. Responden yang pernah mengalami/menjadi korban kriminal online

Terkait usaha pencegahan adanya serangan siber dari respon mitra, yang yakin menjawab sudah melakukan upaya pencegahan hanya $30.8 \%, 38.5 \%$ belum melakukan upaya pencegahan dan $30.8 \%$ belum yakin sudah melakukan tindakan pencegahan seperti pada gambar 7

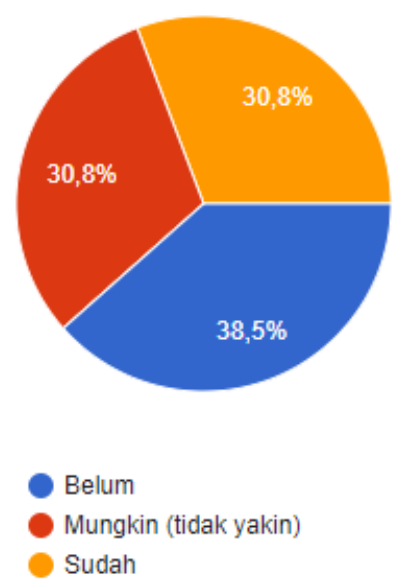

Gambar 7. Upaya pencegahan

\section{Sosialisasi kepada UMKM}

Pelaksanaan PKM berupa webinar online dilaksanakan pada 28 Oktober 2021 secara daring. Pelaksanaan webinar sekaligus sebagai sosialisasi terkait cyber security awareness kepada UMKM diikuti oleh 21 peserta. Proses sosialisasi melalui pemaparan materi yang dilakukan oleh anggota tim pelaksana pengabdian. Gambar 8 dan gambar 9 ilustrasi proses pemaparan materi pada saat sosialisasi. 


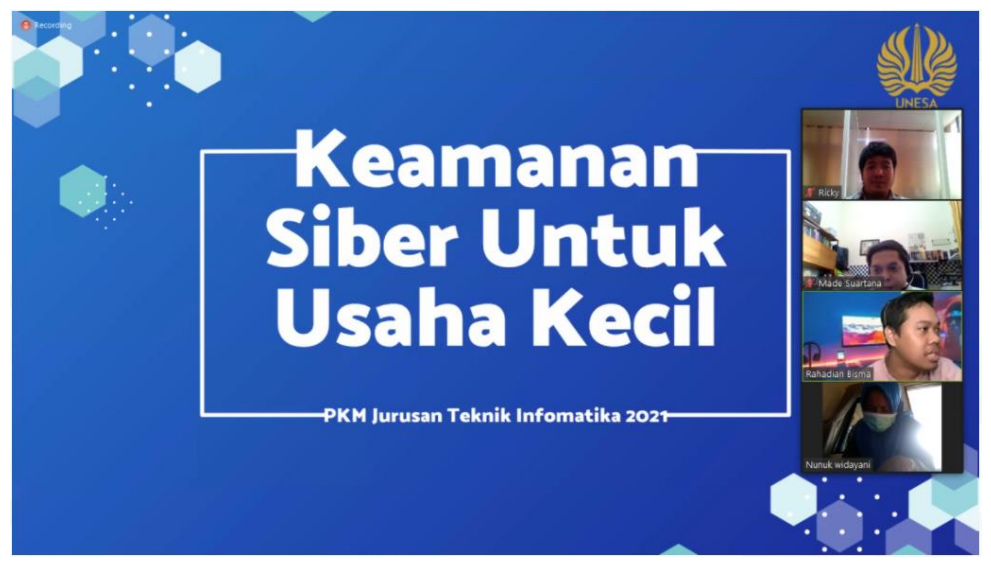

Gambar 8. Pemaparan materi kepada peserta.

Proses pemaparan materi berlangsung selama satu setengah jam. Setelah proses pemaparan materi acara sosialisasi dilanjutkan dengan diskusi dan Tanya jawab dengan peserta.

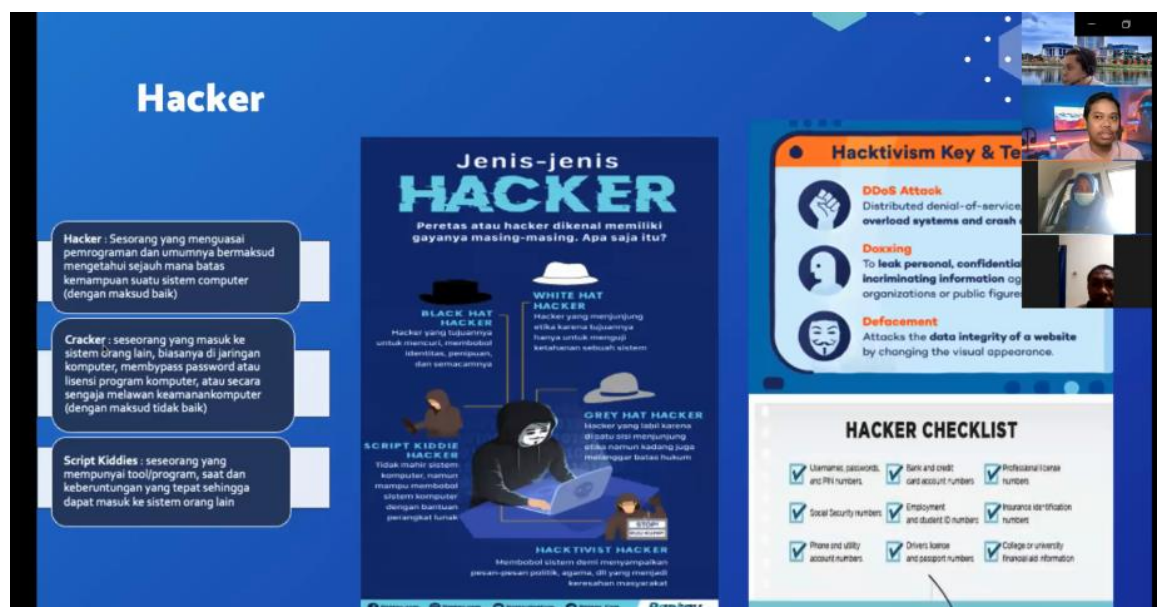

Gambar 9. Pemaparan materi kepada peserta.

Penilaian pelaksanaan PKM ini berdasarkan survei terhadap kepuasan mitra terkait pelatihan yang dilaksanakan. Salah satu poin survei terkait pemahaman peserta terkait materi yang disajikan. Dari gambar 9 dapat dilihat berdasarkan jawaban peserta dengan menggunakan skala Linkert 1(belum paham) sampai 4 (sangat paham), sebanyak $15.4 \%$ menjawab 2, 61.5\% menjawab 3 dan $23.1 \%$ menjawab 4.

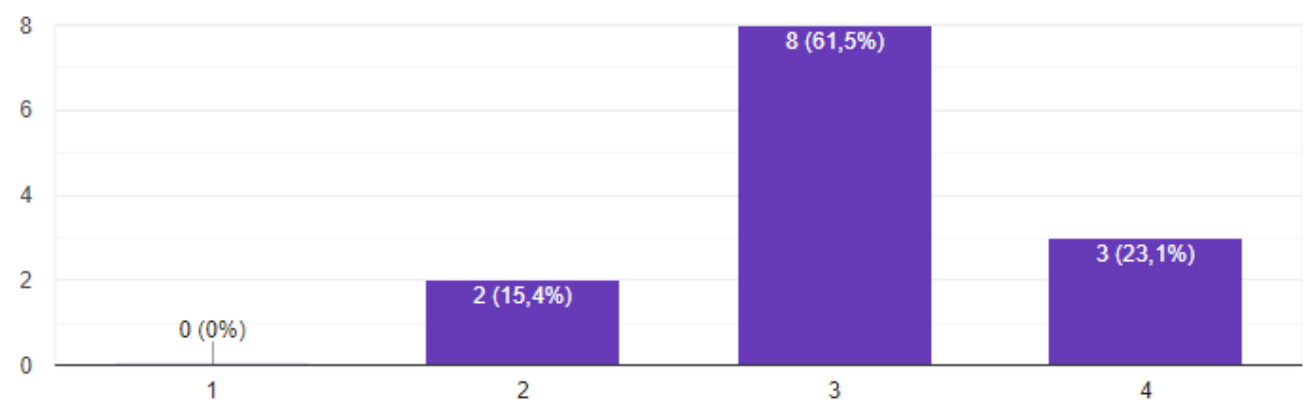

Gambar 9. Respon terkait pemahaman materi 


\section{KESIMPULAN}

Pengenalan Cyber Security Awareness kepada pelaku UMKM sebagai langkah awal dalam mengedukasi pelaku UMKM agar memiliki kesadaran akan bahaya dalam proses transaksi secara digital melalui internet. Manfaat yang diperoleh bagi UMKM melalui melalui pelaksanaan pengabdian kepada masyarakat ini adalah mendapatkan pengetahuan tentang pentingnya kesadaraan tentang ancaman keamanan dalam dunia digital. Serta UMKM memiliki pengetahuan untuk dapat terhindar dari kemungkinan tindak kejahatan cyber. Mengingat maraknya penggunaan media digital lewat internet dalam kegiatan UMKM terutama dalam promosi dan penjualan secara online.

\section{UCAPAN TERIMAKASIH}

Terimakasih kepada Fakultas Teknik Universitas Negeri Surabaya atas pendanaan dalam pelaksanaan pengabdian kepada masyarakat dan kepada mitra pelaksanaan pengabdian kepada masyrakat diantaranya UMKM Mandiri Abadi.

\section{DAFTAR PUSTAKA}

Alkhudhayr, F., Alfarraj, S., Aljameeli, B., \& Elkhdiri, S. (2019). Information Security:A Review of Information Security Issues and Techniques. 2019 2nd International Conference on Computer Applications \& Information Security (ICCAIS), https://doi.org/10.1109/CAIS.2019.8769504

Cindy Mutia Annur. (2020, April 11). UKM Indonesia Jadi Target 192 Ribu Serangan Siber Selama WFH. Https://Katadata.Co.Id/.

Jixing, L., Yu, W., \& Bin, Q. (2018). Discussion on Cyber Security Awareness and Awareness Model Building Based on Connectionism. 2018 IEEE 4th Information Technology and Mechatronics Engineering Conference (ITOEC), 259-263. https://doi.org/10.1109/ITOEC.2018.8740446

Khairunnisak Nur Isnaini, Dina Fajar Sulistiyani, \& Manut Sutrisno. (220 C.E.). Data Security Awarenesssebagai Upaya Peningkatan Literasi Tentang Cyber AttacksdanThreats. JPMB: Jurnal Pemberdayaan Masyarakat Berkarakter, 3(2), 121-132.

Li, Y., \& Liu, Q. (2021). A comprehensive review study of cyber-attacks and cyber security; Emerging trends and recent developments. Energy Reports, 7, 8176-8186. https://doi.org/10.1016/j.egyr.2021.08.126

Miftahurrisqi, Ika Safitri Windiarti, \& Dwi Haryanto. (2021). EDUKASI DAN PENINGKATAN KOMPETENSI IT-SECURITY DAN E-COMMERCE BAGI MAHASISWA MA'HAD ASYSYAFI'I PALANGKARAYA. Martabe: Jurnal Pengabdian Kepada Masyarakat, 4(3), 963969.

Nugrahani, T. S., Ardiyanto, F., \& Umam, S. (2019). CYBER CRIME AWARENESS: INTERNET KNOWLEDGE DAN E-COMMERCE USE PADA UMKM DI KABUPATEN BANTUL YOGYAKARTA. MANAJEMEN DEWANTARA, 3(2), 203-213. https://doi.org/10.26460/md.v3i2.6010

Widnyani, N. M., Astitiani, N. L. P. S., \& Putri, B. C. L. (2021). PENERAPAN TRANSFORMASI DIGITAL PADA UKM SELAMA PANDEMI COVID-19 DI KOTA DENPASAR. Jurnal Ilmiah Manajemen Dan Bisnis, 6(1), 79-87. https://doi.org/10.38043/jimb.v6i1.3093 